\title{
Más allá del nacionalismo: trayectorias etnomusicológicas en Brasil
}

\author{
Suzel Ana Reily
}

En muchas naciones periféricas, tales como Brasil, la investigación musical fue instigada por sentimientos nacionalistas, lo que generó tradiciones de investigación dirigidas a recoger etnografías folclóricas y descriptivas. Esto contrasta con los intereses de investigación en el eje angloamericano, donde las etnografías musicales se emplean para ilustrar perspectivas teóricas de validez universal. Sin embargo, muchas contribuciones importantes a la etnomusicología comprenden estudios en los cuales las propuestas teóricas surgen del material etnográfico. Si esto es cierto, las naciones periféricas se encuentran ahora en una posición particularmente ventajosa para redefinir las normas de la disciplina, debido a su acceso al campo así como a los últimos debates académicos. En este artículo la autora estudia cómo lucha actualmente la etnomusicología brasileña por trascender su herencia nacionalista sin sacrificar su compromiso con la nación. Inicia con un panorama del desarrollo de la investigación musicológica en Brasil desde finales del siglo XIX, observando cómo se estableció la orientación nacionalista y cómo llevó a la construcción de una narrativa canónica que definió a la música brasileña "auténtica". Luego analiza cómo se impugna la narrativa canónica y cómo esto ha llevado al establecimiento de una comunidad de investigación dinámica y madura.

In many peripheral nations, such as Brazil, music research was instigated by nationalist sentiments, which generated research traditions directed toward the collection of folklore and descriptive Ethnography. This contrasts with the research concerns along the Anglo-American axis, where musical Ethnographies are used to illustrate theoretical perspectives of universal validity. However, many major contributions to Ethnomusicology involve studies in which the theoretical propositions emerge out of the Ethnographic material. If this is so, peripheral nations are now in a particularly advantageous position to redefine the standards of the discipline, given their access both to the field and the latest academic debates. This paper examines how Brazilian Ethnomusicology is currently striving to transcend its nationalist heritage without compromising its commitment to the nation. The piece begins with an overview of the development of musicological research in Brazil since the late nineteenth century, looking at how the nationalist orientation was stablished and how it led to the construction of a canonical narrative defining "authentic" Brazilian music. It then looks at how the canonical narrative is being challenged, leading to the stablishment of a dynamic and mature research community.

\footnotetext{
SUZEL ANA REILY: Queen's University Belfast.

Desacatos, núm. 12, otoño 2003, pp. 11-23.

- Traducción de María Jiménez Mier y Terán.
} 
E n muchos lugares del mundo, los estudios etnomusicológicos fueron animados por el surgimiento de sentimientos nacionalistas. En tales contextos, la investigación se ha centrado en la documentación e investigación de los repertorios locales, en un esfuerzo por descubrir aquello que distingue a una nación de otra. Estas tradiciones se basan en la reificación de la nación y a menudo elaboran representaciones esencializadas del carácter nacional, que ocultan las vastas diferencias al interior de las fronteras nacionales. Sin embargo, como se considera que el material etnográfico encarna el "nosotros nacional", las escuelas nacionalistas por lo común generan vastas colecciones de música tradicional y detallados recuentos descriptivos de las actividades y eventos musicales, atribuyendo con ello un gran valor a las manifestaciones de la cultura expresiva.

Esto contrasta radicalmente con los hábitos de investigación que prevalecen a lo largo del eje angloamericano, donde la mirada se dirige al "otro exótico" con el fin de identificar las dimensiones de la musicalidad humana en las diversas culturas. Dentro de esta tradición académica, la etnografía sirve para ilustrar propuestas teóricas de amplia aplicación. Sin embargo, una de las consecuencias de esta tendencia es que cada vez se pone más énfasis en la capacidad que la investigación tiene de generar ideas innovadoras, mientras la descripción etnográfica va perdiendo valor. A medida que esta tendencia se acentúa, la brecha entre la imaginación teórica y la vida de la gente real también se profundiza. No obstante, por su pretensión de validez universal, esta inclinación ha llegado a definir las normas internacionales en la investigación, mientras que las tradiciones nacionalistas se han visto progresivamente marginadas a causa de su aldeanismo. Más aún, el inglés ha sido establecido sin duda alguna como el idioma internacional de la academia.

Vale señalar, empero, que algunas de las monografías anunciadas como grandes contribuciones al campo de la etnomusicología de las décadas pasadas, como es el caso de Sound and Sentiment (1982) de Steven Feld, Why Suyá Sing (1987) de Seeger, y May it Fill your Soul (1994) de Timothey Rice son obras maduras basadas en una larga experiencia de campo. Lo que hace estos estudios particularmente convincentes es la manera como sus incli-

naciones teóricas parecen surgir directamente de la etnografía. Así, estas monografías son fieles a la gente que retratan y a la vez promueven el debate internacional. $\mathrm{Si}$ ésta ha de ser la meta a seguir, los estudiosos que trabajan en contextos periféricos estarían ahora en una posición particularmente ventajosa para redefinir las normas de esta disciplina. Como tienden a salirse de la tradición centrada en los repertorios nacionales, son por lo general muy versados en las músicas locales y su fácil acceso al campo les proporciona los medios para renovar constantemente el material. Por otra parte, la globalización ha abierto el acceso al debate internacional, permitiendo que los estudiosos de lugares periféricos se actualicen en las más recientes tendencias internacionales de esta disciplina. De hecho, las consecuencias de estas circunstancias ya están aflorando, pues en todo el mundo existen diversas comunidades de investigadores, articuladas, llenas de vitalidad y creativamente involucradas en el estudio de la música. A menudo, no obstante, su trabajo ha limitado la visibilidad global, pues operan en contextos periféricos y quizá no dominan el idioma inglés.

Yo diría que éste es el caso de la etnomusicología brasileña contemporánea, pues desde la década de 1990 la investigación musical ha crecido a un ritmo asombroso. Si bien hace unos cinco años no había licenciaturas en etnomusicología en Brasil, hoy en día existen etnomusicólogos de base en varias universidades y diversas instituciones ofrecen licenciaturas en etnomusicología. El creciente interés por este campo llevó a fundar la Asociación Brasileña de Etnomusicología en 2001, durante la Conferencia Anual de la ICTM, celebrada en Río de Janeiro, con una membresía inicial de 64 investigadores, incluyendo a académicos y estudiantes de posgrado. Este es, por lo tanto, un momento particularmente interesante para la etnomusicología brasileña. Nuevas publicaciones sobre música brasileña, escritas por investigadores brasileños, están apareciendo a un ritmo sin precedentes y muchos de estos estudiosos destacan por su compleja argumentación crítica, basada en una sólida documentación etnográfica. Sin embargo, cabe señalar que muchos de los estudiosos brasileños que trabajan en proyectos de interés etnomusicológico no se identifican a sí mismos como etnomusicólogos. Además de los etnomusicólogos 
con credenciales en la investigación musical en Brasil también están involucrados musicólogos, maestros de música, antropólogos, sociólogos, folcloristas, periodistas, lingüistas e historiadores, entre otros académicos.

Si bien hoy en día los enfoques teóricos y metodológicos de los estudios brasileños distan mucho de estar unificados, existe, no obstante, una orientación distinta que data de los inicios de la investigación musical en este país. Desde las primeras compilaciones folclóricas de fines del siglo XIX a los últimos escritos de intelectuales brasileños contemporáneos, el interés por estudiar la música y la cultura brasileñas ha sido impulsado por el deseo de entender mejor al país y de contribuir, de alguna manera, a resolver sus problemas. Por lo tanto, la investigación siempre ha sido una actividad inherente a Brasil. Pero lo que se consideraba la problemática más apremiante del país y la manera como la música y la investigación musical habrían de contribuir a su solución, han variado con el tiempo.

En su empeño por lograr sus objetivos, los estudiosos brasileños han luchado por estar al tanto de las últimas ideas originadas en el "centro". Pero en vez de apropiárselas solamente, las han adaptado a sus propias preocupaciones. Mi propósito en este trabajo, por lo tanto, es analizar cómo los debates entre los investigadores de la música en Brasil han dado forma a los temas y estilos de la investigación local a lo largo del siglo XX, generando finalmente las tendencias actuales. Sostengo que esta trayectoria ofrece un ejemplo de cómo un proyecto nacionalista trasciende y adquiere un perfil de investigación internacional sin que el sentido de responsabilidad nacional de los investigadores se vea comprometido.

\section{INVESTIGACIÓN MUSICALY CONCIENCIA NACIONAL}

Desde tiempos coloniales, los misioneros, viajantes y residentes, hicieron recuentos de las actividades musicales de Brasil, pero la investigación conciente de la música brasileña por parte de estudiosos brasileños es relativamente reciente; surge con el nacimiento de la conciencia nacional. A fines del siglo XIX, cuando se elabo-

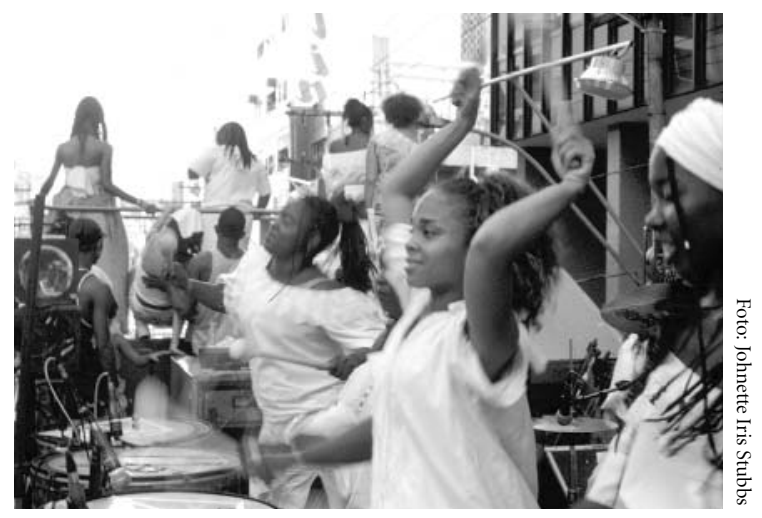

raron las primeras grandes colecciones de folclor, las letras de las canciones recibieron mucha atención, pero raras veces se registró la música que las acompañaba. Quizá sólo la obra de Mário de Andrade (1893-1945) fue retomada por un (etno)musicólogo brasileño, y a partir de entonces diversos investigadores se han ocupado en documentar las diferentes formas de expresión musical que se encuentran al interior del país.

El surgimiento de la conciencia cultural nacional de Brasil coincidió con el despertar de los sentimientos republicanos hacia finales de la era imperial. De hecho, en 1889 Brasil fue declarado una república y el emperador Dom Pedro II y su familia fueron exiliados a Europa. Aunque Brasil se había vuelto un Estado independiente en 1822, la mirada cultural de las elites del país seguía dirigida principalmente a Europa. Con la República surgió el llamado a los brasileños a valorar su excepcional patrimonio cultural y nació una moda por los exotismos del país (Tinhorão 1986:35). Se generaron entonces algunas de las primeras grandes publicaciones de folclor nacional escritas por eminentes intelectuales como Amadeu Amaral, Arthur Azevedo, Mello Moraes Filho, Sílvio Romero y otros más.

No obstante, estos primeros proyectos distaban de ser optimistas en sus representaciones sobre el lugar que el país ocupaba ante el resto del mundo; surgieron más bien dentro del debate relativo a cómo explicar mejor los impedimentos al desarrollo del país. Inspirándose en las teorías raciales y climáticas que en ese momento prevalecían en Europa, se consideraba que la inferioridad de la 
cultura brasileña radicaba en la configuración racial del país y en su clima tropical. Sin embargo, como Roberto Ventura (1991: 12) apunta, los intelectuales brasileños no sólo se apropiaron de los modelos europeos en sus obras, sino que los reinterpretaron y adaptaron a sus propios proyectos. Según las nociones arias, la capacidad intelectual de los indios y africanos era significativamente inferior a la de los blancos europeos, y según la lógica de los efectos del clima en las formaciones sociales, las vaporosas condiciones del hemisferio sur sirvieron para explicar la indolencia y holgazanería del carácter brasileño. Por consiguiente, las soluciones propuestas giraban en torno a la necesidad de "blanquear" a la población, algo que los más optimistas pensaban podría ocurrir en uno o dos siglos.

Uno de los más ardientes promotores de la institución de políticas de blanqueamiento en Brasil fue Silvio Romero, quien también realizó algunos de los primeros estudios de textos de canciones brasileñas, incluyendo Cantos populares do Brasil (1993 [1985]) y Estudo sobre a poesia popular no Brasil (1870-1880) (1888). Romero sostenía los intelectuales brasileños se dedicaban a estudiar lo que distinguía a Brasil de las naciones desarrolladas. Por lo tanto, refutaba la idealización que los novelistas y poetas nacionalistas, como José de Alencar, hacían de los (amer)indios y criticaba su rechazo por los africanos, quienes, sostenía, tenían una presencia más fuerte en Brasil y eran racialmente superiores a los brasileños nativos. En su afán por presentar a Brasil como "realmente" era, finalmente Romero formuló un discurso que constituiría la base de los movimientos nacionalistas del siglo XX: concluía que aquello que distinguía a Brasil de otras naciones era el mestizaje del país; los mestiços, afirmaba, habían sido los agentes de mayor influencia para establecer una cultura brasileña diferente.

A principios del siglo XX se aceptaba la idea de que Brasil era un país único porque derivaba del encuentro y mezcla de amerindios, africanos y europeos; pero el argumento de que esto explicaba el atraso del país no era muy reconocido. Las propuestas que surgieron para abordar un cambio de perspectiva se centraban en las relaciones estructurales entre Brasil y Europa; ahora se tomaría en cuenta esta relación para explicar la dependencia cultural de Brasil. En un editorial escrito en 1916, por ejemplo, Júlio Mesquita (citado en Martins, 1970: 142-3) sostiene:

\begin{abstract}
Desde nuestro nacimiento hemos existido como una nación, sea como Imperio sea como República, bajo el tutelaje directo o indirecto (si no político, al menos moral) de Europa. Pensamos con un cerebro extranjero; nos visten sastres extranjeros; comemos una dieta extranjera y para coronar tal acto de servilismo, muy a menudo en nuestra patria sofocamos nuestra lengua materna para hablar una lengua extranjera.
\end{abstract}

Esta dependencia había evitado que Brasil se familiarizara consigo mismo y que adquiriera "el espíritu para avanzar solo hacia una proyección vigorosa y resplandeciente de su propia personalidad".

Para Gilberto Freyre (1968 [1936]) el servilismo era fundamentalmente un mal de las elites urbanas brasileñas. Sostenía que el impedimento de los brasileños para desarrollar una conciencia nacional era la presencia de la corte portuguesa en Brasil. Para huir de la amenaza francesa, la familia real de Portugal, con un cortejo de más de 10000 súbditos, llegó a Río de Janeiro en 1808, instaurando un impulso civilizador que en 1822 transformaría al tranquilo pueblo de 50 ooo habitantes en una bulliciosa capital imperial con una población de 100 ooo habitantes (Skidmore, 1999: 36).

$\mathrm{Al}$ igual que otros monarcas anteriores a él, Dom João VI era un gran promotor de las artes y las ciencias, y durante su estancia embelleció la ciudad con la Biblioteca Nacional, la Escuela de Medicina, los Jardines Botánicos, la Escuela de Bellas Artes y muchas instituciones más. La música recibió atención especial por parte del monarca; fundó la Capilla Imperial que sostenía a cincuenta cantantes, una orquesta completa y dos maestros de capilla (Mariz, 1983: 49) y construyó el Teatro Real de San Juan, copia del gran Teatro de San Carlos de Lisboa, que introdujo la ópera en la vida social de las elites de Río. Freyre sostenía que esta "invasión lusitana” llevaba a los brasileños a ocultar los elementos sincréticos de su cultura local, ya que eran vistos por los recién llegados como la encarnación de la inferioridad cultural colonial.

A medida que se afianzaban discursos semejantes a éste, las políticas de blanqueamiento eran rechazadas y 
la responsabilidad de construir una identidad nacional fundada en la cultura híbrida del país se convertía en un proyecto para la intelligentsia. Una de las explicaciones más coherentes de este proyecto fue formulada por Mário de Andrade en 1928, con la publicación de Ensaio sobre a música brasileira. De Andrade era uno de los principales líderes intelectuales del movimiento modernista brasileño de tendencia nacionalista que agrupó a artistas de diversos campos, incluyendo literatura, pintura, escultura, arquitectura y música. Como lo he dicho en otro trabajo (1994), el Ensaio... hacía un llamado a los círculos musicales del momento, argumentando que Brasil podría ser liberado de su servidumbre cultural por medio del mundo artístico. Estaba en sus manos romper el hábito de imitar los modelos culturales europeos y construir una cultura autónoma que reflejara la psique brasileña. Su mensaje dirigido a los compositores tenía por intención alentarlos a inspirar su trabajo en el legado cultural de la nación; y sus extensas colecciones del repertorio nacional amasadas durante sus múltiples expediciones a diversas regiones del país ofrecieron la materia prima para este empeño.

El interés musical de De Andrade no se limitaba a la recopilación, también incursionó en el estudio del repertorio nacional con un afán por definir la manifestación musical de la psique nacional. Al igual que sus predecesores, estaba en contacto con los debates académicos que se llevaban a cabo en Europa y su trabajo estaba muy influido por Lévy-Bruhl, Taylor, Frazer, Freud y Marx (Schelling, 1991: 195). Pero el uso que hacía de estos teóricos era selectivo y creativo, fusionando las corrientes internacionales en boga con los debates y preocupaciones locales. De acuerdo con el pensamiento de su tiempo, aceptaba el mito de la etnia brasileña de tres razas, pero sobre todo le interesaba mostrar de qué manera las contribuciones de los grupos raciales se habían fusionado en las expresiones originales de la musicalidad brasileña. La producción musicológica de De Andrade es demasiado extensa como para ser valorada en este trabajo y ha sido tema de innumerables investigaciones (véase especialmente Naves, 1998; Reily, 1994; Schelling, 1991; Travassos, 1997). Sin embargo, vale la pena observar que su representación de la psique brasileña es algo irreverente, extravagante y maliciosa, e invoca los estereotipos del flojo mestiço del trópico de épocas pasadas. Pero en vez de aparecer como un obstáculo para el desarrollo, al igual que el mestiço de Romero, la figura híbrida de De Andrade es una posibilidad del Nuevo Mundo, cuyo carácter no puede ser impedido por las fuerzas represivas de las viejas tradiciones (del Viejo Mundo).

Un mestiço un poco menos ambiguo surgiría en la década de 1930 en la obra clásica de Gilberto Freyre, $\mathrm{Ca}$ sa-grande e senzela (1981 [1933]). Freyre sostenía que la informalidad del sistema colonial y la ausencia de exclusivismo racial de los portugueses creaban un contexto de relaciones interraciales benigno, donde los blancos, los negros y los mestiços trabajaban felices hombro con hombro para alcanzar metas comunes. En su obra, el mestiço híbrido es saludado como el símbolo de la unidad nacional, materialización de la síntesis de las diferentes categorías sociales. El mestiço de Freyre fue mejorado por Sérgio Buarque do Holanda (1936), quien representaba al brasileño como un hombre "cordial". La representación del brasileño como un mestiço "amigable", "feliz", "cordial" y "trabajador" pronto se convertiría en un estereotipo de la población en su conjunto.

Esta representación del carácter brasileño embonaba bien con los objetivos populistas de Getúlio Vargas, quien llegó al poder en 1930 y consolidó su régimen en 1937 con la institución del Estado Novo. El régimen de Vargas, que duraría hasta $1945,{ }^{1}$ apuntaba hacia la industrialización, y este impulso iba complementado con un fuerte discurso nacionalista, cuya finalidad era integrar las clases populares a las estructuras políticas y económicas del país. El proyecto nacionalista se centraba en la imagen del "cordial mestiço", un trabajador híbrido dignificado, orgulloso de contribuir a la prosperidad del país. La maquinaria propagandística de Vargas promovía vigorosamente los emblemas del mestizaje como símbolos de identidad nacional y la música desempeñaba un papel central en las definiciones de lo que se entendería por cultura nacional.

\footnotetext{
${ }^{1}$ Vargas fue reelecto para la presidencia en 1950, cargo que ocupó hasta su suicidio en 1954.
} 
El comienzo del régimen de Vargas coincidió con el surgimiento de la samba, un estilo popular híbrido que proporcionaba al Estado Novo una forma musical fabricada acorde con la agenda nacionalista. La samba fue cooptada y configurada a través de la censura para promover "lo brasileño". Con sus asociaciones carnavalescas, la samba podía ser recibida como la feliz integración de los diferentes grupos culturales y raciales del país; y a través de la radio, la imagen fue propagada a lo largo de Brasil. Cantantes populares, tales como Ary Barroso, Orlando Silva, Carmen Miranda, Francisco Alves y otros fueron cooptados por la Radio Nacional, propiedad del Estado, para cantar las glorias de Brasil. Y así, lo que razonablemente podría ser considerado el estilo local de Río de Janeiro se convirtió pronto en uno de los símbolos más duraderos de la identidad nacional brasileña.

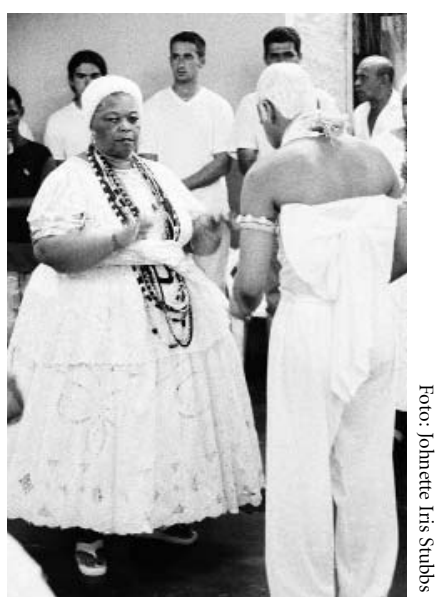

torsionadamente, los objetivos trazados en Ensaio... de De Andrade. De este modo, particularmente en el terreno de los estudios de música folclórica, durante este periodo la investigación se llevó a cabo básicamente como una "operación de rescate" y para proporcionar materia prima a las grandes artes.

Incluso después de la caída del Estado Novo, la orientación nacionalista siguió infiltrándose en la obra de muchos estudiosos brasileños, sea de música folclórica, popular o culta; y siguió atrincherada durante toda la dictadura militar, que duró desde 1964 hasta las elecciones presidenciales directas de 1985. A pesar del vínculo entre investigación y construcción de la nación, muchos investigadores llevaron a cabo estudios meticulosos y detallados sobre diversos aspectos de la música brasileña. Un área que se desarrolló de manera particularmente notable pertenece a la historiografía de la música brasileña, tanto en lo relativo a la música culta como a la popular, con notables contribuciones de Renato Almeida (1942), Vasco Mariz (1983 [1981]), José Maria Neves (1981), José Ramos Tinhorão (1986 [1974]) y muchos más.

No es extraño que la historiografía se haya convertido en una preocupación central. Según John Tosh (1984), la escritura de la historia es un modo de forjar la identidad social mediante la creación de la memoria colectiva que establece la relación de un grupo con el pasado. Pero el pasado de la historiografía es una "representación de lo pasado" (Tonkin, 1992), que se construye en el presente en términos de las preocupaciones contemporáneas. De manera análoga a lo que João Hernesto Weber (1997) apunta respecto a la historiografía literaria brasileña, los autores de historias de la música brasileña a menudo han proyectado sus propias agendas nacionalistas hacia el pasado y sus narraciones lo representan como un proceso continuo e inevitable, donde la música producida en Brasil se nacionaliza progresivamente. Este proceso de nacionalización ha sido representado a través de una sucesión cronológica de estilos, que llegó a adquirir estatus canó-

2 Debe recordarse, sin embargo, que Alvarenga dedicó toda una vida a la organización y publicación de los manuscritos de De Andrade sobre música brasileña, haciendo posible que hoy en día se puedan conseguir sin dificultad. 
nico y a definir lo que constituye la "auténtica" música nacional brasileña. ${ }^{3}$

\section{CONSTRUCCIÓN DEL CANON}

Las historias de la música brasileña, sea que aborden la música culta o la popular, por lo común empiezan con un periodo formativo que generalmente abarca la era colonial, donde se muestra cómo el encuentro entre los europeos, los africanos y los amerindios generó una infinidad de formas híbridas difusas. A finales del siglo XVII algunos de estos estilos híbridos son considerados suficientemente estables como para ser identificados y nombrados. Los géneros que con más frecuencia se consideran como las primeras formas musicales expresivas "auténticamente brasileñas" son la modinha y el lundu. Si bien estos estilos siguieron diferentes procesos de desarrollo histórico —el primero "africanizó" una forma europea, el segundo "europeizó" una forma africana - finalmente se fusionaron en el contexto del salón, al punto de volverse prácticamente indistinguibles uno del otro, ambos comprendidos por el término genérico de modinha. Por ser considerada un elemento central del desarrollo de la cultura musical nacional brasileña, la modinha ha sido objeto de una vasta investigación, incluyendo los importantes estudios de Mário de Andrade (1980 [1930]), Mozart de Aráujo (1963) y João Batista Siqueira (1979), al igual que otros estudios de menor envergadura. ${ }^{4}$

Tanto en Portugal como en Brasil el término moda era utilizado para referirse a cualquier tipo de canción folclórica, pero a finales del siglo XVIII su forma diminutiva, modinha, fue asociada en Portugal con un tipo particular de canción de amor de salón operístico. Aunque también existía una forma portuguesa de modinha, se la distinguía de la modinha brasileña, más rítmica y sincopada.

${ }^{3}$ Cabe señalar que este canon también se repite en el caso de muchos estudiosos no brasileños, como sucede con Appleby (1983), Béhague (1979), McGowan y Pessanha (1991), Schreiner (1993 [1977]) y varios más.

4 Recientemente Manuel Veiga (1998) realizó un estudio de esta vasta literatura.
Los recuentos que se han escuchado sobre el desarrollo de la variante brasileña de la modinha comienzan típicamente con Domingos Caldas Barbosa (1738-180o), un nativo de Río de Janeiro, quien apareció en los salones portugueses alrededor de 1775 con su viola de arame (guitarra de cuerdas de alambre), usada para acompañar un vasto repertorio de tonadas moralmente cuestionables a las que denominaba modinhas y lundus. Sus presentaciones causaron estupor - así como enorme fascinaciónentre la gente educada de la metrópolis, resaltando las nociones de rusticidad y moralidad degenerada de los coloniales híbridos.

Basándose en partituras de modinhas brasileñas de finales del siglo XVIII, algunas (si no es que todas) de Caldas Barbosa, Gerard Béhague (1968: 68) señalaba que la primera modinha brasileña, a diferencia de su contraparte portuguesa, hacía mucho uso de las síncopas, rasgo atribuido a la herencia africana en la Colonia. Junto con estos rasgos "brasileños", las muy ornamentadas líneas melódicas de estas primeras piezas prueban la marcada influencia del bel canto italiano, tan apreciado entre las elites portuguesas de la época. Comprensiblemente, se ha argumentado que Caldas Barbosa creó la modinha brasileña fusionando las prácticas musicales concretas que había asimilado en Brasil con los estilos de salón dominantes que encontró en Lisboa (Kefer, 1977: 15). Un estudio muy reciente de estas partituras, realizado por Edilson de Lima (2001: 52), enfatiza la original "personalidad" de esta colección, ese je-ne-sait-quoi que destacaba del repertorio de las demás modinhas de la época:

Algumas coisas européias, e sem dúvida, muita coisa brasileira, não só pela letra, mas pela sonoridade, pelo estacato monótono da viola, pela simplicidade harmônica, pela melodia sincopada e toda recortada, pelos suspiros e ais!

En otras palabras, las modinhas de Caldas Barbosa son representadas como algo más que una fusión técnica de los elementos europeos y africanos; son vistas como articulaciones de la desenfadada incorporación en el compositor de una musicalidad brasileña única.

Caldas Barbosa fue quizá la mayor fuerza que provocó el furor por la modinha en la metrópolis a finales del siglo XVIII, pero fueron los portugueses quienes vol- 
vieron a introducir el género en Brasil unas décadas más tarde, cuando la familia real llegó a Río. Cuando la modinha regresó a lo que entonces era el Virreinato de Brasil, había sufrido una notable domesticación. Los vergonzosos temas que habían ruborizado a la gente educada cedieron su lugar a formas más respetuosas de expresión amorosa. Poco después de su repatriación, la modinha - en su forma domesticada, por supuesto- ganó popularidad en los salones de Río, donde siguió siendo popular durante el siglo XIX. Pero el lugar de la viola, el instrumento utilizado para el acompañamiento, fue ocupado por el piano, una de las grandes novedades que introduciría la corte portuguesa. Estos modernos y nobles instrumentos rápidamente se convirtieron en importantes símbolos de estatus entre las elites brasileñas. Las familias con los medios suficientes se arremolinaron para adquirir uno; $\mathrm{y}$ al aprender a tocarlo, las damas jóvenes empezaron a aumentar el número de sus prospectos matrimoniales. Los compositores brasileños abastecieron el mercado con una corriente continua de nuevas modinhas, con contribuciones provenientes de tan eminentes músicos como José Maurício Nunes Garcia (1767-1830), maestro de capilla de la Capilla Imperial, Francisco Manuel da Silva (1795-1865), el compositor del himno nacional de Brasil y Carlos Gomes (1836-1896), el compositor de ópera más renombrado del país.

Aunque en el contexto del salón el instrumento favorito para acompañar la modinha era el piano, el género no permaneció confinado a este escenario por mucho tiempo y tampoco quedó restringido al piano. Los músicos populares de Río tomaron la modinha y los guitarristas callejeros, los modinheiros, se volvieron muy comunes en la capital imperial; algunos de ellos recibieron ovaciones de la elite carioca y de los turistas extranjeros. El trabajo de Joaquim Manuel, guitarrista sin entrenamiento formal, por ejemplo, llamó la atención del compositor austriaco Sigismund Neukomm (1778-1858), un discípulo de Haydn, cuya estancia en Río duró de 1816 a 1821; en París editó una recopilación de modinhas del músico popular, que él mismo armonizó para el piano. Joaquim Manuel también llamó la atención del francés Louis Freycinet, quien lo consideraba un "raro talento" (ver M. de Araújo, 1969: 69). Otros modinheiros popula-

res, tales como Xisto Bahia (1841-1894) y Catulo da Paixão Cearence (1866-1946), también fueron muy aclamados.

Así como la modinha se deslizó a las calles, los sucesivos ciclos de bailes europeos, como la polka, la cuadrilla, el chotís y el vals, que cruzaron el Atlántico y fueron favorablemente acogidos por los salones brasileños, fueron retomados por los músicos de la calle. Dentro de estos círculos se desarrollaría un estilo instrumental popular conocido como el choro. ${ }^{5}$ Según los recuentos comunes, el choro nació alrededor de 1870 no tanto como un género musical distinto sino como una manera local de ejecutar las tonadas dancísticas, especialmente la polka. En sus inicios el estilo era ejecutado por un conjunto instrumental llamado un trio de pau e corda (trío de cuerdas y maderas), formado por una flauta de ébano, que llevaba la línea melódica, un cavaquinho (instrumento de cuatro cuerdas parecido al ukulele), que ofrecía un acompañamiento armónico de percusión, y una guitarra, que proporcionaba el bajo. Con el tiempo, el choro se volvería más virtuoso e improvisador; y a finales del siglo otros instrumentos melódicos empezarían a sustituir a la flauta, como el bandolín, el clarinete y el oficleide. Chorões (choro/músicos callejeros) generalmente tocaban en las fiestas de las casas de gente de la misma clase social así como en cafés, hoteles y cabarets, a menudo sólo a cambio de comida y bebida.

Poco tiempo después de desarrollarse entre músicos callejeros, el choro regresó a las esferas respetables cuando varios compositores con formación musical, como es el caso de Chiquinha Gonzaga (1847-1935), Alexandre Levy (1864-1892) y Ernesto Nazaré (1863-1933), entre otros, empezaron a crear choros para el piano. Vale la pena señalar, no obstante, que a menudo estos compositores llamaron a sus obras tangos brasileños; distanciándolos de la forma callejera, esperaban conferirles mayor respetabilidad. No fue sino varias décadas después que Héctor Villa-Lobos (1887-1959) crearía su conocido Choro No. 1 (1921) para solo de guitarra, enalteciendo el estilo popular.

\footnotetext{
5 Sobre el choro, véase Appleby (1983: 70-3), Cazes (1998), Schreiner (1993: 85-101), Tinhorão (1986: 103-10, 1997: 107-25), Vasconcelos (1988), entre otros.
} 
La modinha y el choro han sido objeto de especial interés por parte de los escritores de historias de la música brasileña, pues han sido definidos como los géneros mediante los cuales por primera vez se pudo identificar una musicalidad brasileña distinta; $y$ a partir de entonces, todos los demás géneros que se integrarían al canon habrían de adaptarse a los mismos criterios. Ambos géneros representan formas híbridas de elementos europeos y africanos integrados para crear algo nuevo y exclusivamente brasileño. Más aún, iban dirigidos tanto a las clases altas como a las bajas, uniéndolas a través de una psique brasileña común que atravesaba las líneas divisorias socioeconómicas y raciales. De esta manera, las historias de la música popular al igual que las historias de la música culta han dedicado un espacio a la modinha y al choro, a menudo evidenciando que la distinción entre música popular y música culta de Brasil es muy poco clara, particularmente durante el siglo XIX. ${ }^{6}$

Sin embargo, a principios del siglo XX las historias de la música culta y la música popular generalmente se separan. La primera se involucra con el movimiento Modernista, mientras que la segunda se convierte en samba. Mi objetivo no es, por supuesto, resumir aquí los contenidos de las historias de la música brasileña, sino señalar cómo éstas han elaborado textos canónicos que han definido los momentos significativos del desarrollo del repertorio nacional. En música popular, el canon del siglo XX comprende la samba, el bossa nova y la MPB (que significa Música Popular Brasileira). Por consiguiente, lo definido en términos nacionales se limita al gusto de las clases medias urbanas. Incluso, desde la época de la modinha lo nacional ha sido constituido de los géneros más prominentes emanados de la capital cultural del país, Río de Janeiro. De este modo todos los demás estilos desarrollados dentro del territorio nacional han llegado a ser identificados como músicas regionales. Incluso el baião, que alcanzó relevancia nacional a finales de los años cuarenta, sigue siendo vinculado con el nordeste. Como afirma Maria Elizabeth Lucas (2000: 43):

\footnotetext{
${ }^{6}$ Este tema fue retomado por Santuza Cambraia Naves (1998) respecto a los inicios del siglo XX. Este autor argumenta sobre la relación que existe entre modernismo y samba y que en ambos universos lo humilde se reconcilia con lo sublime.
}

los recuentos históricos lineales que describen la sucesión de los movimientos musicales de la música popular brasileña, presentándola como única, independiente y hegemónica, han creado una narración mítica sobre quienes están en el centro y han hecho invisibles a quienes se encuentran en los márgenes.

\section{TRASCENDIENDO EL NACIONALISMO}

Con la apertura política de 1985, la orientación nacionalista de la investigación musical brasileña empezó a someterse a una mirada crítica sistemática y a saludar una tendencia distinta, que tiende al desmantelamiento de las mitologías sobre las tres etnias, las cuales han dominado la esfera musicológica en el siglo XX. En términos generales, podríamos decir que el debate actual se centra en torno a los dos lados de la misma moneda: por una parte, hay investigadores trabajando en evaluaciones críticas sobre la forma como la música ha estado implicada en la construcción de la identidad nacional brasileña; y por la otra, hay quienes requieren de una noción de música brasileña capaz de abarcar las múltiples identidades construidas musicalmente dentro del territorio nacional.

Aunque el papel desempeñado por la música en la construcción de la identidad nacional brasileña ha recibido especial atención durante algún tiempo (ver Ortiz, 1986; Reily, 1994; Squeff y Wisnik, 1983), la publicación del libro de Hermano Vianna (1995 [traducción al inglés 1999] ), O mistério do samba, redefine los términos de este debate, cuestionando los textos comunes sobre el surgimiento de la samba en la historiografía de la música brasileña. Mientras que las historias canónicas destacan dos momentos distintos - una fase inicial cuando la samba es reprimida, seguida por un repentino ascenso de popularidad que convierte a la samba en el ritmo nacional- Vianna sostiene que esta historia fue construida como un medio para crear la unidad brasileña híbrida esposada por el régimen de Vargas. Más que un repentino triunfo sobre la represión, Vianna muestra de qué manera la samba surgió de las continuas interacciones entre las diferentes clases sociales de Río de Janeiro, las cuales unieron sus fuerzas para crear una música nacional. Mientras Vianna se enfoca a estudiar los discursos en torno a 
la samba, Carlos Sandori (2001) traza el desarrollo musicológico del género, esbozando los diálogos que lo llevan a su transformación y consolidación musical.

No obstante, mirando desde afuera del centro cultural de Río de Janeiro, surge una perspectiva diferente del canon. Basándose en estudios de género, en su obra sobre los gustos de las clases medias en Montes Claros, Minas Gerais, Martha Tupinambá de Ulhôa (2000) muestra cómo la modinha y la samba-canção han sido utilizadas de diversas formas en un entorno provinciano y patriarcal. Ulhôa sostiene que en este contexto, donde las mujeres son las responsables de salvaguardar la integridad moral de sus familias, el contenido romántico de estos géneros desempeñó un papel central, ofreciendo modelos de relaciones entre géneros que son armónicos con el sistema patriarcal, saludando el amor romántico como un medio para escapar de la mediocridad de la vida cotidiana. Así, en contraste con los discursos que los ideólogos estaban elaborando, en este contexto la celebración de la identidad nacional brasileña tenía una importancia secundaria frente a las audiencias de samba.

Algunos investigadores también están buscando la manera de trascender la orientación nacionalista en el estudio de la samba. Mariana Carneiro da Cunha (2001) y Luciana Prass (2001), por ejemplo, se están acercando a la samba desde una perspectiva práctica de ejecución, viendo a las escuelas de samba como contextos de creación de música de la comunidad y esferas de instrucción musical. Quizá la propuesta más compleja sea la de Samuel Araújo (1992), quien ha desarrollado el concepto metodológico de "trabajo acústico". El concepto esboza la tarea etnomusicológica como el estudio de la obra que va más allá —y ha ido más allá— de la práctica musical. Implica una investigación dialógica, tanto sincrónica como diacrónicamente, de la interacción entre la música, las múltiples relaciones que se establecen al hacer música, los diversos recursos empleados en la producción de música, y los discursos y diálogos en torno a la música y su producción. Este enfoque subraya la importancia de investigar el conocimiento que la gente tiene de la samba en relación con la importancia ideológica que ésta comporta para la nación. Además de que este modelo es particularmente pertinente para el estudio de la samba, dados los poderosos discursos que la acompañan, el enfoque metodológico tiene una aplicación mucho más extensa.

También es importante señalar el innovador enfoque que el lingüista Luiz Tatit (1996) hace del repertorio canónico y que va dirigido al estudio de la relación entre habla y canto. Basándose en un numeroso inventario de conocidas canciones populares, Tatit sostiene que todas las canciones populares (brasileñas) se originan en el habla. Sus trabajos han avivado el interés de los estudios de la música brasileña por la "palabra cantada", como puede observarse en la reciente publicación de un volumen basado en las conferencias presentadas en la Primera Reunión para el Estudio de la Palabra Cantada, llevada a cabo en Río en el 2000 (ver Matos, Travassos y Medeiros, 2001).

Con el desafío a la agenda nacionalista se ha abierto un espacio para la investigación de una amplia gama de estilos musicales que estaban marginados por el canon. Aunque hoy los géneros periféricos son reconocidos e investigados, quizá sea justo decir que los estilos de la música popular están recibiendo una atención mayúscula por parte de los estudiosos brasileños y que el enfoque histórico sigue siendo muy fuerte. Esto se puede confirmar con el ambicioso proyecto creado por Editora 34 en 1995, que establece la serie "Ouvido musical" (ahora "Todos os cantos”), bajo la dirección de Tárik de Souza. Originalmente esta serie comprendería 24 volúmenes, pero ha continuado creciendo para abarcar géneros tan dispares como frevo, música sertaneja, rock brasileño y afro-reggae. Si bien en su conjunto estas publicaciones son muy detalladas, la mayoría de los autores de la serie son periodistas y sus intereses giran más en torno a la documentación meticulosa que alrededor del debate teórico.

Paralelamente a esta colección, varios científicos sociales también han dirigido su atención a los estilos de música popular que no se encuentran dentro del canon. Aquí también algunos investigadores han emprendido enfoques historiográficos, pero se han interesado más por ver de qué manera los estilos se articulan con la experiencia social y la identidad de quienes están involucrados en su ejecución, producción y recepción. Éste, por ejemplo, es el caso de dos recientes estudios de Luiz Gonzaga y del baião del nordeste (Ramalho, 2000; Vieira, 2000). 
Otros investigadores han hecho estudios por periodos, como es el caso del teórico de la comunicación Waldenyr Caldas (1995) y del historiador José Geraldo Vinci de Moraes (1997), quien ofrece panoramas de la vida musical cotidiana en la ciudad de São Paulo a principios del siglo XX, una historia que fue oscurecida durante mucho tiempo por la mirada de la historiografía musical brasileña, centrada en Río. Al enfocar la primera etapa del desarrollo industrial en São Paulo, los autores muestran cómo las tensiones fueron animadas por los nuevos ideales modernistas, por las inmigraciones masivas y las cambiantes relaciones laborales que surgieron entonces e incidieron en la producción y recepción musical de la floreciente metrópolis.

También se está investigando una extensa gama de mundos musicales diversos, incluyendo las tradiciones "folclóricas" rurales, las tradiciones afro-brasileñas y las músicas de las sociedades amerindias. Esta literatura es muy extensa para ser abordada aquí; pero sí quiero señalar que la mayoría de las veces estos estudios hacen uso de modelos interpretativos que tratan de presentar el punto de vista de "los nativos".7 Asimismo quiero añadir que las perspectivas etnográficas también han influido en la investigación de las músicas populares. Tras la publicación del libro de Hermano Vianna, O mundo funk carioca (1988), por ejemplo, nació el interés por las subculturas urbanas de los jóvenes y se disparó una serie de proyectos antropológicos, muchos de los cuales se basan en la Escuela de Chicago y en estudios culturales británicos (véase por ejemplo Diógenes, 1998; Herschmann, 1997; Vianna, 1997). Incluso, los enfoques etnográficos están modelando la investigación sobre música colonial, a medida que diversos estudiosos, como José Maria Neves (1987), José Leonel Gonçalves Dias (1999), Edésio de Lara Melo (2001) y otros, han comenzado a investigar las prácticas musicales contemporáneas de este repertorio

\footnotetext{
7 Pruebas de esta diversidad pueden encontrarse en algunas de las nuevas revistas dedicadas a la investigación musical y recientemente publicadas en Brasil, como es el volumen 11 de Horizontes antropológicos, "Música e sociedade" (1999), editado por Maria Elizabeth Lucas, y el volumen 4 de Série Estudos, "Pesquisas recentes em estudos musicais no Mercosul” (2000), editada por Maria Elizabeth Lucas y Rafael José de Menezes Bastos.
}

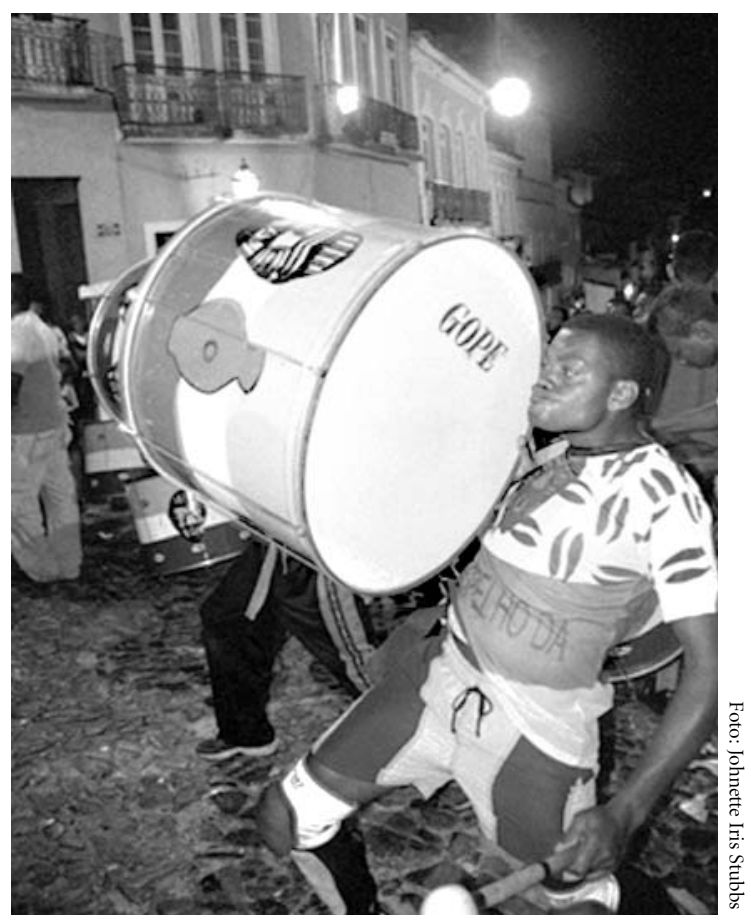

en las anteriores regiones mineras de Minas Gerais. Tal vez el tema más relegado dentro de la investigación musical brasileña sea el de las tradiciones musicales de los grupos inmigrantes, aunque actualmente existen unas cuantas investigaciones de doctorado encargadas de estos asuntos. Otra esfera que los investigadores deberían atender es la vida musical de las comunidades brasileñas en el extranjero así como las músicas brasileñas en contextos judaicos. ${ }^{8}$

Con este panorama general he intentado retratar la vitalidad y madurez de la investigación contemporánea de la música en Brasil. Aunque la mayor parte de la producción etnomusicológica brasileña está escrita en portugués, algunos estudiosos han publicado en el extranjero, haciendo su trabajo accesible a un público más amplio. ${ }^{9}$

\footnotetext{
${ }^{8}$ Aunque desconozco si existen brasileños que trabajen sobre las músicas brasileñas en la diáspora, algunos investigadores no brasileños se han acercado al tema, incluyendo a Jochen Eisentraut (2001) y Asa Veghed (2001).

${ }^{9}$ Existe una importante aportación brasileña en las siguientes compilaciones de volúmenes, publicados fuera de Brasil: Castelo-Branco (1997), Perrone y Dunn (2001) y Reily (2000).
} 
A medida que los investigadores brasileños abren nuevos caminos para acercarse a la comprensión de las músicas del país, nuevamente están explorando las perspectivas globales, vinculándolas con las preocupaciones locales. La diversidad de enfoques teóricos, que abarcan debates sobre identidad, género, semiótica, teoría de la ejecución, teoría subcultural y varias otras perspectivas, indica la envergadura del contacto que los estudiosos brasileños mantienen con la comunidad académica más extensa. Más aún, algunos investigadores están generando modelos de validez de las músicas brasileñas que pueden tener una aplicación más amplia entre diferentes culturas. Aunque comprometida con un diálogo internacional, la fuerza subyacente que impulsa la investigación en Brasil sigue basándose en un decidido compromiso por entender la realidad nacional. La utilidad de cualquier propuesta teórica se mide por su capacidad para apoyar semejante tarea. Este modus operandi da por resultado un estilo documental de gran riqueza etnográfica, que da cuenta del compromiso del investigador con la historiografía futunacional e internacional.

\section{Bibliografía}

Almeida, Renato, 1942, História da música brasileira, F. Briguit \& Comp., Río de Janeiro.

Andrade, Mário de, 1962 [1928], Ensaio sobre a música brasileira, Martins, São Paulo.

—, 1964 [1930], Modinhas imperiais, Martins, São Paulo.

Appleby, David P., 1983, The Music of Brazil, University of Texas Press, Austin.

Araújo, Mozart de, 1963, A modinha e o lundu no século XVIII, Ricordi, São Paulo.

Araújo, Samuel, 1992, Acoustic Labour in the Timing of Everyday Life: a Critical Contribution to the History of Samba in Río de Janeiro, tesis de doctorado, University of Illinois.

Béhague, Gerard, 1968, "Biblioteca da Ajuda (Lisbon) MSS 1595/1596: Two Eighteenth Century Anonymous Collections of Modinhas", Yearbook of the Inter-American Institute for Musical Research, IV.

—, 1979, Music in Latin America: an Introduction, Prentice-Hall, Englewood Cliffs.

__ 1991, "Reflections on the Ideological History of Latin American Ethnomusicology”, en B. Nettl y P. V. Bohlman (eds.), Comparative Musicology and Anthropology of Music, University of Chicago Press, Chicago, pp. 56-68.

Buarque de Holanda, Sérgio, 1971 [1936], Raízes do Brasil, José Olympio, Río de Janeiro.

Caldas, Waldenyr, 1995, Luz neon: canção e cultura na cidade, SESC/Studio Nobel, São Paulo.

Carneiro da Cunha, Mariana, 2001, The Transmission of Musical Knowledge: a Case Study in "Mocidade Independente de Padre Miguel" Samba School, ponencia presentada en la XXXVI Conferencia Mundial ICTM, Río de Janeiro.

Castelo-Branco, Salwa El-Shawan (ed.), 1997, Portugal e o mundo: o encontro de culturas na música/Portugal and the World: the Encounter of Cultures in Music, Dom Quixote, Lisboa.

Cazes, Henrique, 1998, Choro: do quintal ao Municipal, Editora 34 , São Paulo.

Eisentraut, Jochen, 2001, "Samba in Wales: Making Sense of Adopted Music", British Journal of Etnomusicology, vol. 10, núm. 1, pp. 85-105.

Feld, Steven, 1982, Sound and Sentiment: Birds, Weeping, Poetics and Song in Kaluli Expression, University of Pennsylvania Press, Philadelphia.

Freyre, Gilberto, 1968 [1936], Sobrados e mucambos, José Olympio, Río de Janeiro.

—_, 1981 [1933], Casa-grande e senzala, José Olympio, Río de Janeiro.

Gonçalves Dias, José Leonel, 1999, A música em Prados, tesis doctoral, Universidade de São Paulo.

Kiefer, Bruno, 1977, A modinha e o lundu, URGS/Movimento, Porto Alegre.

Lima, Edilson de, 2001, As modinhas do Brasil, EdUSP, São Paulo.

Lucas, Maria Elizabeth (ed.), 1999, Música e sociedade, tema de Horizontes Antropológicos, núm. 11.

_, 2000 , "Gaucho musical regionalism", British Journal of Ethnomusicology, vol. 9, núm. 1, pp. 41-60.

— sas recentes em estudos musicais no Mercosul, tema de Série Estudos, núm. 4.

Mariz, Vasco, 1983 [1981], História da música no Brasil, Civilização Brasileira, Rio de Janeiro.

Martins, Wilson, 1970, The Modernist Idea: a Critical Survey of Brazilian Writing in the 2oth Century, trad. por J. E. Tomlins, New York University Press, Nueva York.

Matos, Cláudia Neiva de, Elizabeth Travassos y Fernanda Teixeira de Medeiros (eds.), 2001, Ao encontro da palavra cantada: poesia, música e voz, Letras 7, Río de Janeiro. 
McGowan, Chris y Ricardo Pessanha, 1991, The Billboard Book of Brazilian Music: Samba, Bossa Nova and the Popular Sounds of Brazil, Guiness Publishing, Londres.

Melo, Edésio de Lara, 2001, A música da Semana Santa em quatro cidades da região dos Campos das Vertentes (MG), MA dissertation, Universidade do Rio de Janeiro.

Moraes, José Geraldo Vinci de, 1997, Sonoridades paulistanas: final do século XIX ao início do século XX, FUNARTE, Río de Janeiro.

Naves, Santuza Cambraia, 1998, O violão azul: modernismo e música popular, Fundação Getúlio Vargas, Río de Janeiro.

Neves, José Maria, 1981, Música contemporânea brasileira, Ricordi, São Paulo.

— 1987, A Orquestra Ribeiro Bastos e a vida musical em São João del Rei, tesis para la cátedra de "La evolución de la música”, Universidad de Río de Janeiro.

Ortiz, Renato, 1986, Cultura brasileira e identidade nacional, Brasiliense, São Paulo.

Perrone, Charles y Christopher Dunn (eds.), 2001, Brazilian Popular Music and Globalization, University Press of Florida, Gainesville.

Prass, Luciana, 2001, The Ethnopedagogy of Teaching and Learning Music in the Percussion Section (Bateria) of a Samba School: Research Among the "Bambas de Orgia", ponencia presentada en la XXXVI Conferencia Mundial ICTM, Río de Janeiro.

Ramalho, Elba Braga, 2000, Luiz Gonzaga: a síntese poética e musical do sertão, Terceira Margem, São Paulo.

Reily, Suzel Ana, 1994, "Macunaíma’s Music: National Identity and Ethnomusicological Research in Brazil", en M. Stokes (ed.), Ethnicity, Identity and Music: the Musical Construction of Place, Berg, Oxford, pp. 71-96.

- (ed.), 2000, Brazilian Musics, Brazilian Identities, edición especial de British Journal of Ethnomusicology, vol. 9, núm. 1.

Rice, Timothy, 1994, May it Fill your Soul: Experiencing Bulgarian Music, University of Chicago Press, Chicago.

Romero, Sílvio, 1888, Estudo sobre a poesia popular no Brasil (1870-1880), Laemmert, Río de Janeiro.

— 1985 [1883], Cantos populares do Brasil, Ed. Itatiaia, Belo Horizonte.

Sandroni, Carlos, 2001, Feitiço decente: transformações do samba no Rio de Janeiro (1917-1933), Jorge Zahar, Río de Janeiro.

Schelling, Vivian, 1991, A presença do povo na cultura brasileira: ensaio sobre o pensamento de Mário de Andrade e Paulo Freire, traducido por F. Carotti, Universidade Estadual de Campinas, Campinas.

Schreiner, Claus, 1993 [1977], Música Brasileira: a History of Popular Music and the People of Brazil, Marion Boyars, Nueva York.
Seeger, Anthony, 1987, Why Suyá Sing: a Musical Anthropology of an Amazonian People, Cambridge University Press, Cambridge.

Siqueira, João Batista, 1979, Modinhas do passado, Folha Carioca, Río de Janeiro.

Skidmore, Thomas E., 1999, Brazil: Five Centuries of Change, Oxford University Press, Nueva York.

Squeff, Enio y José Miguel Wisnik (eds.), 1983, O nacional e o popular na cultura brasileira, Brasiliense, São Paulo.

Tatit, Luiz, 1996, O cancionista, EdUsP, São Paulo.

Tinhorão, José Ramos, 1986 [1974], Pequena história da música popular: da modinha ao tropicalismo, Art Editora, São Paulo.

—_, 1997 [1966], Música popular - um tema em debate, Editora 34, São Paulo.

Tonkin, Elizabeth, 1992, Narrating our Pasts: the Social Construction of Oral History, Cambridge University Press, Cambridge.

Tosh, John, 1984, The Pursuit of History, Longman, Londres. Travassos, Elizabeth, 1997, Os mandarins milagrosos: arte e etnografia em Mário de Andrade e Béla Bartók, FUNARTE/ Jorge Zahar, Río de Janeiro.

Ulhôa, Martha Tupinambá de, 200o, "Música romântica in Montes Claros: Inter-Gender Relations in Brazilian Popular Song", British Journal of Ethnomusicology, vol. 9, núm. 1, pp. 11-40.

Vasconcelos, Ary, 1988, "Choro: um ritmo bem brasileiro", en T. de Souza et al. (eds.), Brasil musical, Edições de Arte, Río de Janeiro, pp. 70-99.

Veiga, Manuel, 1998, "O estudo da modinha brasileira”, $L a-$ tin American Music Review, vol. 19, núm. 1, pp. 47-91.

Ventura, Roberto, 1991, Estilo tropical: história cultural e polêmicas literárias no Brasil, Companhia das Letras, São Paulo.

Veghed, Asa, 2001, The Case of the Samba School in Sweden, ponencia presentada en la XXXVI Conferencia Mundial ICTM, Río de Janeiro.

Vianna, Hermano, 1988, O mundo do funk, Jorge Zahar, Río de Janeiro.

__ 1995, O mistério do samba, Jorge Zahar, Río de Janeiro. (ed.), 1997, Galeras cariocas: territórios de conflitos e encontros culturais, Editora UFRJ, Río de Janeiro.

_ 1999, The Mystery of Samba: Popular Music and National Identity in Brazil, traducido por J.C. Chasteen, North Carolina University Press, Chapel Hill.

Vieira, Sulamita, 2000, O sertão em movimento: a dinâmica da produção cultural, Annablume, São Paulo.

Weber, João Hernesto, 1977, A nação e o paraíso: a construção da nacionalidade na historiografia literária brasileira, Editora da UFSC, Florianópolis. 